УДК: 539.22

\title{
ПОЛУЧЕНИЕ, МОРФОЛОГИЯ И ЭЛЕКТРОХИМИЧЕСКИЕ СВОЙСТВА ГИБРИДНЫХ МАТЕРИАЛОВ ТРИПСИН - УГЛЕРОДНЫЕ НАНОТРУБКИ
}

\author{
(С2018 Э. А. Карлос, И. И. Долгих \\ Воронежский государственный университет, Университетская пл., 1, 394018 Воронеж, Россия \\ e-mail:dolgih_igor@yahoo.com \\ Поступила в редакцию 27.04.2018
}

\begin{abstract}
Аннотация. Изучены электрохимические свойства гибких печатных электродов, модифицированных гибридным материалом трипсин - углеродные нанотрубки. Обнаружена зависимость вольтамперных характеристик электродов от присутствия казеина. Полученные структуры могут быть использованы в качестве биосенсора для применения в пищевой промышленности.
\end{abstract}

Ключевые слова: трипсин, углеродные нанотрубки, печатные электроды, биосенсор, вольтамперные характеристики, электрохимическая ячейка.

DOI: https://doi.org/10.17308/kcmf.2018.20/526

\section{ВВЕДЕНИЕ}

Сенсоры играют большую роль в повседневной жизни, такими датчиками являются наши собственные чувства. Человеку необходимо знать значения бесчисленного количества ненаблюдаемых переменных без использования датчиков [1]. Биосенсор представляет собой аналитическое устройство, включающее в себя материал биологического распознавания (ферменты, антитела, клетки, нуклеиновую кислоту и т. д.), прикрепленные к детектору [2]. Биосенсоры могут быть классифицированы по типу иммобилизованного биорецептора или по типу преобразователя (электрохимические, термометрические, пьезоэлектрические, фотометрические) [3]. Наибольшее распространение в быту получили электрохимические биосенсоры глюкозы, основанные на использовании фермента глюкооксидазы.

Сенсоры применяются в различных областях: медицина, диагностика, сельское хозяйство, ветеринария, бактериальный, вирусный и промышленный контроль, горнодобывающая промышленность, охрана окружающей среды, военная промышленность [4]. К 2020 году объём продаж биосенсоров достигнет 5 миллиардов долларов [5]. Биосенсоры, основанные на использовании ферментов, получили распространение в медицине и пищевой промышленности.
Казеин молочного белка является одним из наиболее потребляемых в рационе человека. На территории Российской Федерации, как и во всём мире, существуют стандарты, которые контролируют использование казеина (ГОСТ 31689-2012, ГОСТР 536672009). Организация Объединенных Наций имеет свои собственные стандарты (CODEXSTAN 2901995). Казеин - это основной белок коровьего молока [6]. Он имеет множество применений не только в пищевой промышленности, но и в производстве клея [7], пластмассы [8,9], текстильных волокон [10], а также в косметологии и фармации $[11,12]$. Казеин может вызывать аллергию, что делает важным его экспресс-идентификацию [13].

Трипсин - фермент класса гидролаз, расщепляющий пептиды и белки, обладает также эстеразной (гидролиз сложных эфиров) активностью. Трипсин представляет собой бесцветное кристаллическое вещество с температурой плавления около $150{ }^{\circ} \mathrm{C}$. Таблицы рентгеноструктурного анализа трипсина хранятся в базе данных под кодовым названием 2 ptc. Трипсин используется в медицине для расщепления омертвевших тканей, при этом живую ткань он не расщепляет из-за наличия в ней ингибитора. Кроме того, способность трипсина селективно гидролизировать некоторые связи позволяет использовать его при анализе структуры бел- 
ков. В промышленности трипсин применяют для размягчения кожи [14].

Нанокомпозиты представляют собой такие элементы, в которых один компонент имеет нанометровый размер, в то время как гибридные материалы, используемые для обучения, имеют наноуровни. Основное различие заключается в том, что нанокомпозиты имеют новое свойство.

Гибридный материал представляет собой соединение, которое образовано из двух материалов, объединенных на молекулярном уровне. В большинстве случаев он формируется из неорганических и органических компонентов. Соединение этих наноразмерных материалов может дать в результате более однородные матрицы или новый материал, который имеет характеристики каждого компонента.

Целью нашего исследования является обнаружение казеина за счет электрохимических процессов на гибких печатных электродах, покрытых гибридным материалом трипсин - углеродные нанотрубки. Изготовленные в Московском государственном университете электрохимические электроды послужили материалом для исследования. Мы модифицировали поверхность этих электродов с помощью трипсина и получили статистические результаты по обнаружению казеина.

\section{МАТЕРИАЛЫ И МЕТОДЫ ИССЛЕДОВАНИЯ}

В качестве исходных компонентов были взяты следующие вещества: трипсин фирмы «BP biomedicals»; углеродные нанотрубки (УНТ) фирмы «Вауer»; печатные электроды производства Московского государственного университета, изготовлены из серебряной пасты, при этом рабочий и вспомогательный электроды были покрыты графитной пастой, а электрод сравнения имел состав $\mathrm{Ag} / \mathrm{AgCl}$; казеин фирмы «Sigma». Растворы трипсина и казеина приготовили в $0.2 \mathrm{M}$ фосфатном буфере $\mathrm{pH}=6.5$.

Одна из проблем углеродных нанотрубок состоит в том, что они имеют тенденцию ухудшать свои характеристики со временем, однако их можно растворить не только в воде, но и в различных веществах, таких как хлороформ, дихлорметан, ацетон, метанол, этанол с использованием органической функционализации. В нашем случае мы готовили коллоидный раствор в концентрациях $10^{-5}$ и $2.5 \cdot 10^{-5}$ М углеродных нанотрубок в дистиллированной воде с помощью ультразвукового диспергирования при частоте 22 кГц и мощности 100 Вт в течение 15 минут (УЗГ 12).
Исследования методом атомно-силовой микроскопии (ACM) проводили на микроскопе Solver P47 Pro. Анализ морфологии наноструктур осуществляли в 2 стадии:

1. Анализ чистого фермента трипсина. Раствор трипсина концентрации $10^{-5} \mathrm{M}$ наносился на пластину слюды, после чего пластина просушивалась при комнатной температуре в течение 24 часов.

2. Анализ системы трипсин + углеродные нанотрубки. Смешивали 2.5 мл раствора трипсина концентрации $10^{-5} \mathrm{M}$ с 0.5 мл коллоидного раствора углеродных нанотрубок. Затем смесь наносили на пластину слюды, после чего пластина просушивалась при комнатной температуре в течение 24 часов.

Методом циклической вольтамперометрии [16] исследовали вольтамперные характеристики (BAX) электродов в анализируемом растворе. Всего использовалось 50 гибких печатных электродов: 20 из них были модифицированы только трипсином концентрации $10^{-5} \mathrm{M}$, а остальные 30 (по 15 на каждый образец) - гибридным материалом трипсинУНТ при концентрации трипсина $10^{-5} \mathrm{M}$ и концентрациях углеродных нанотрубок $10^{-5}$ и $2.5 \cdot 10^{-5} \mathrm{M}$. Модификацию проводили путем нанесения на поверхность электрода 10 мкл препарата (чистого трипсина или смеси трипсина и УНТ), после чего электроду давали высохнуть в течение 24 часов при комнатной температуре.

Электрохимическую ячейку изготавливали следующим образом. На модифицированный электрод наносили 100 мкл раствора казеина концентрации $10^{-5} \mathrm{M}$. Далее, измеряли вольтамперные характеристики (BAX) электрохимической ячейки с помощью потенциостата IPC-ProMF. Использовался треугольный входной сигнал, время дискретизации составляло 10 мкс, подаваемое напряжение изменялось от -1 до +1 В. Измерение сигнала производилось в течение двух минут при комнатной температуре.

\section{ЭКСПЕРИМЕНТАЛЬНЫЕ РЕЗУЛЬТАТЫ И ИХ ОБСУЖДЕНИЕ}

АСМ анализ чистого трипсина. Как показано на рис. 1, фермент распространился по поверхности подложки пористой структуры. Поры имеют глубину 20 нм и, практически, равномерно распределены по поверхности подложки. Их диаметр колеблется от 20 до 120 нм. На АСМ-изображениях хорошо видны небольшие пики, выступающие из пористой поверхности подложки. Они имеют высоту от 6 до 7 нм. На рис. 1 также можем наблю- 


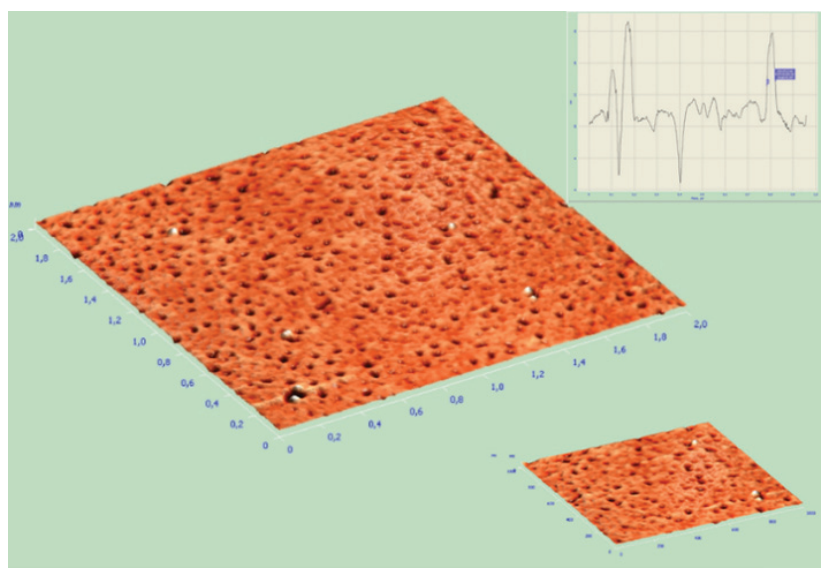

Рис. 1. АСМ-изображения трипсина на пластине слюды

[Fig. 1. AFM images of trypsin on a mica plate]

дать, как формируются четвертичные глобулярные структуры энзима.

АСМ анализ фермента с добавлением УНТ. При создании гибридных материалов с использованием трипсина большую роль играют углеродные нанотрубки, которые радикально меняют адгезию фермента к поверхности, что приводит к возникновению изолированных кластеров гибридного материала (рис. 2). Можно сказать, что поверхность нанотрубок полностью покрывается энзимом. При

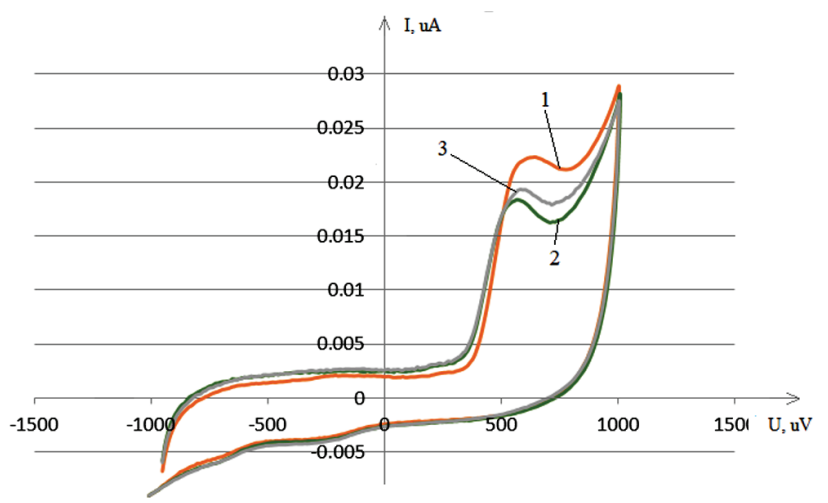

Рис. 3. Измеренные ВАХ трипсина с добавлением УНТ при концентрации казеина $10^{-5} \mathrm{M} /$ л. 1 - трипсин концентрации $10^{-5} \mathrm{M} ; 2$ - смесь трипсина концентрации $10^{-5} \mathrm{M}$ и УНТ концентрации $10^{-5} \mathrm{M} ; 3$ - смесь трипсина концентрации $10^{-5} \mathrm{M}$ и УНТ концентрации

$$
2.5 \cdot 10^{-5} \mathrm{M}
$$

[Fig. 3. The measured $I-V$ characteristic of trypsin with the addition of CNT at a casein concentration of $10^{-5} \mathrm{M}$.

1 - trypsin concentrations of $10^{-5} \mathrm{M} ; 2$ - mixture of trypsin with a concentration of $10^{-5} \mathrm{M}$ and a CNT concentration of $10^{-5} \mathrm{M} ; 3$ - mixture of trypsin with a concentration of $10^{-5} \mathrm{M}$ and a CNT concentration of $2.5 \cdot 10^{-5} \mathrm{M}$ ]

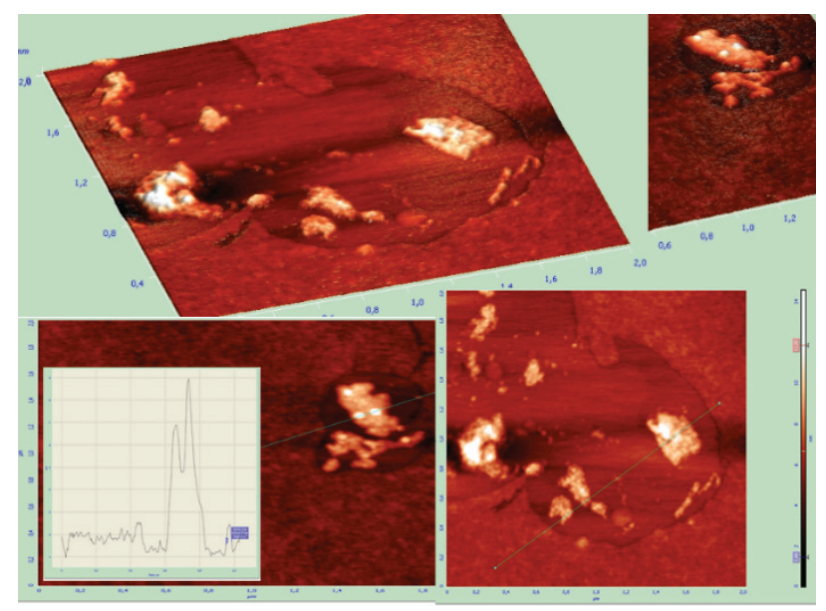

Рис. 2. АСМ изображения системы трипсин - УНТ на пластине слюды

[Fig. 2. AFM images of the trypsin-CNT system on a mica plate]

этом образуются структуры с максимальной высотой от 9 до 11 нм.

Результаты измерений ВАХ. На рис. 3 представлены кривые BAX, на которых обнаружены характерные пики в диапазоне 500 и 700 микровольт. Испытания с электродами, модифицированными гибридными материалами, показали лучшее время отклика, чем с электродами, модифицированными ферментом трипсином. Вероятно, гибридные материалы способствуют линейности вольтамперометрических характеристик при обнаружении казеина.

\section{ВЫВОДЫ}

В результате экспериментов установлено, что поверхность углеродистых нанотрубок полностью покрывается трипсином, при этом не происходит инактивация фермента. Показано, что электроды, модифицированные ферментом трипсином и УНТ, обладают способностью детектировать казеин. Модифицированные трипсином и УНТ печатные электроды перспективны в использовании в пищевой промышленности для обнаружения казеина в сырье.

Авторы выражают благодарность Холявке Марине Геннадьевне и Королевой Виктории Александровне за помощь в проведении экспериментов.

Выражаем благодарность Центру коллективного пользования научным оборудованием Воронежского государственного университета за активную поддержку.

\section{СПИСОК ЛИТЕРАТУРЫ}

1. Wang J. // Electroanalysis, 2001, vol. 13, № 12, pp. 983-988. DOI: https://doi.org/10.1002/15214109(200108)13:12<983::AID-ELAN983>3.0.CO;2-\# 
2. Claudio Jimenez C., Daniel E. Leon P. // Vitae, revista de la facultad de química farmacéutica, 2009, vol. 16, № 1, p. 144-154.

3. Nambiar S., Yeow J. T. W. // Biosensors and Bioelectronics, 2011, vol. 26, № 5, pp. 1825-1832 DOI: https://doi.org/10.1016/j.bios.2010.09.046

4. Sadana A. Binding and Dissociation Kinetics for Different Biosensor Applications Using Fractals. Elsevier Science, 2007, 384 p. DOI: https://doi.org/10.1016/B9780-444-52784-4.X5000-X

5. Grand View Research. Biosensors Market Analysis By Application (Medical applications, Food Toxicity Detection, Industrial Process Control, Agriculture, Environment) By Technology (Thermal Biosensors, Electrochemical Biosensors, Piezoelectric Biosensors, Optical Biosensors) By End-use (Home Healthcare Diagnostics, Point of Care Testing, Food Industry, Research Laboratories). Report. 2020. U.S., 2015, p. 91.

6. Naifeng $\mathrm{Xu}$, Yanjiao Wang, Li Pan, Xinlin Wei \& Yuanfeng Wang // Food and Agricultural Immunology, 2017, vol. 28, pp. 1105-1115. DOI: https://doi.org/10.1080/0954 0105.2017 .1328662

7. Ashley J., Shukor Y., D’Aurelio R., Trinh L., Rodgers T. L., Temblay J., Pleasants M., Tothill I. E. // ACS Sensors, 2018, vol. 3, № 2. pp. 418-424. DOI: 10.1021/ acssensors. $7 \mathrm{~b} 00850$

8. Raji Majumder, Samudra Prosad Banik, Suman Khowala // Food Chemistry, 2015, vol. 173, pp. 441-448. DOI: https://doi.org/10.1016/j.foodchem.2014.10.027

9. Tague E. L. Casein. Its Preparation, Chemistry and Technical Utilizations. D. Van Nostrand company, New York, USA, 1926, $218 \mathrm{p}$

10. Yasumitsu H. Serine Protease Zymography: LowCost, Rapid, and Highly Sensitive RAMA Casein Zymography. In book: Zymography. Methods and Protocols. Eds. by
Wilkesman J., Kurz L. Humana Press, 2017, vol. 1, pp. 1324. DOI: $10.1007 / 978-1-4939-7111-4$

11. Kaner J., Ioras F., Ratnasingam J. // Journal of Plastics History, 2017, vol. 2, p. 1.

12. Bier M. C., Kohn S., Stierand A., Grimmelsmann N., Homburg S. V., Rattenholl A., Ehrmann A. // IOP Conf. Ser.: Mater. Sci. Eng., 2017, vol. 254, p. 192004. DOI: 10.1088/1757-899X/254/19/192004

13. Cheema M., Hristov A. N., Harte F. M. // J. Dairy Sci., 2017, vol. 100, iss. 11, pp. 8670-8679. DOI: http:// dx.doi.org/10.3168/jds.2017-12631

14. Khafallah I., Boutebba A., Ali. T. // J. Chem. Pharm. Res., 2015, vol. 7, p. 926-930.

15. Ruettimann K. W., Ladisch M. R. // Enzyme Microb. Technol., 1987, vol. 9, pp. 578-579. DOI: https://doi. org/10.1016/0141-0229(87)90109-8

16. Farrell J. H. M., Malin E. L., Brown E. M., Qi P. X. // Current Opinion in Colloid \& Interface Science, 2006, vol. 11, pp. 135-147. DOI: https://doi.org/10.1016/j. cocis.2005.11.005

17. Holt C., Carver J. A., Ecroyd H., Thorn D. C. // Journal of Dairy Science, vol. 96, № 10, 2013. p. 61276146. DOI: https://doi.org/10.3168/jds.2013-6831

18. Ferrandini E., Castillo M., Lypez M. B., Laencina J. // An. Vet. (Murcia), 2006, vol. 22, pp. 5-18.

19. Kinsella J. E. // CRC Crit. Rev. Food Sci. Nutr., 1984, vol. 21, iss. 3, pp. 197-262. DOI: https://doi.org/10.1080/1 0408398409527401

20. Guadix A., Guadix E. M., Pбez-duecas M. P., Gonzбlez-tello P., Camacho F. // Ars Pharmaceutica, 2000, vol. 41, № 1, pp. 79-89.

21. Thesvenot D. R., Toth K., Durst R.A., Wilson G. S. // Pure Appl. Chem., 1999, vol. 71, № 12, pp. 2333-2348.

22. Bahr J. L.; Tour J. M. // Chem. Mater., 2001, vol. 13, iss. 11, pp. 3823-3824. DOI: 10.1021/cm0109903

\title{
PRODUCTION, MORPHOLOGY AND ELECTROCHEMICAL PROPERTIES OF HYBRID MATERIALS TRYPSIN - CARBON NANOTUBES
}

\author{
(C) 2018 E. A. Karlos, I. I. Dolgih \\ Voronezh State University, 1 Universitetskaya pl., 394018 Voronezh, Russia \\ e-mail:dolgih_igor@yahoo.com \\ Received 27.04.2018
}

\begin{abstract}
This study is dedicated to trypsin - carbon nanotube hybrid materials, and the possibility of their use in biosensor devices. The morphology of the enzyme - nanotube materials have been studied with AFM microscopy. The volt-ampere characteristics of the materials have been measured with potentiometric methods. It has been shown that the enzyme interacts with the carbon nanotube in the solution by covering its surface and creation of a hybrid material without tis inactivation. The pure enzyme on the surface of mica creates small peaks protruding from the porous surface of the substrate. They have a height of 6 to $7 \mathrm{~nm}$. The quaternary globular structures of the enzyme is visible. When creating hybrid materials using trypsin, carbon nanotubes play an important role, which radically change the adhesion of the enzyme to the surface, which leads to the appearance of isolated clusters
\end{abstract}


of a hybrid material. The surface of nanotubes is completely covered by the enzyme. In this case, structures with a maximum height of $9 \mathrm{~nm}$ to $11 \mathrm{~nm}$ are formed. It has been shown that the voltampere characteristic of the resulting hybrid material is sensitive to the presence of casein. The curves of the I-V characteristic have characteristic peaks in the range of 500 and 700 microvolts. The tests with electrodes modified with hybrid materials showed better response times than electrodes modified with pure trypsin. It is likely that hybrid materials contribute to the linearity of the voltmetrometric characteristics when detecting the casein.

It has been shown that the screen-printed electrodes modified by trypsin and carbon nanotubes are promising in use in the food industry to detect casein in raw materials.

Keywords: trypsin, carbon nanotubes, printed electrodes, biosensor, volt-ampere characteristics, electrochemical cell.

DOI: https://doi.org/10.17308/kcmf.2018.20/526

\section{ACKNOWLEDGEMENTS}

We thank Holyavka Marina G. and Koroleva Viktoria A. for assistance with experiments and measurements.

The research results were obtained with equipment of Voronezh State University Centre for Collective Use of Scientific Equipment.

\section{REFERENCES}

1. Wang J. Electroanalysis, 2001, vol. 13, no. 12, pp. 983-988. DOI: https://doi.org/10.1002/15214109(200108)13:12<983::AID-ELAN983>3.0.CO;2-\#

2. Claudio Jimenez C., Daniel E. Leon P. Vitae, revista de la facultad de química farmacéutica, 2009, vol. 16, no. 1, p. 144-154.

3. Nambiar S., Yeow J. T. W. Biosensors and Bioelectronics, 2011, vol. 26, no. 5, pp. 1825-1832 DOI: https://doi.org/10.1016/j.bios.2010.09.046

4. Sadana A. Binding and Dissociation Kinetics for Different Biosensor Applications Using Fractals. Elsevier Science, 2007, 384 p. DOI: https://doi.org/10.1016/B9780-444-52784-4.X5000-X

5. Grand View Research. Biosensors Market Analysis By Application (Medical applications, Food Toxicity Detection, Industrial Process Control, Agriculture, Environment) By Technology (Thermal Biosensors, Electrochemical Biosensors, Piezoelectric Biosensors, Optical Biosensors) By End-use (Home Healthcare Diagnostics, Point of Care Testing, Food Industry, Research Laboratories). Report. 2020. U.S., 2015, p. 91.

6. Naifeng $\mathrm{Xu}$, Yanjiao Wang, Li Pan, Xinlin Wei \& Yuanfeng Wang. Food and Agricultural Immunology, 2017, vol. 28, pp. 1105-1115. DOI: https://doi.org/10.1080/0954 0105.2017.1328662

7. Ashley J., Shukor Y., D’Aurelio R., Trinh L., Rodgers T. L., Temblay J., Pleasants M., Tothill I. E. . ACS Sensors, 2018, vol. 3, no. 2. pp. 418-424. DOI: 10.1021/ acssensors. $7 \mathrm{~b} 00850$

8. Raji Majumder, Samudra Prosad Banik, Suman Khowala . Food Chemistry, 2015, vol. 173, pp. 441-448. DOI: https://doi.org/10.1016/j.foodchem.2014.10.027
9. Tague E. L. Casein. Its Preparation, Chemistry and Technical Utilizations. D. Van Nostrand company, New York, USA, 1926, 218 p.

10. Yasumitsu H. Serine Protease Zymography: LowCost, Rapid, and Highly Sensitive RAMA Casein Zymography. In book: Zymography. Methods and Protocols. Eds. by Wilkesman J., Kurz L. Humana Press, 2017, vol. 1, pp. 1324. DOI: $10.1007 / 978-1-4939-7111-4$

11. Kaner J., Ioras F., Ratnasingam J. Journal of Plastics History, 2017, vol. 2, p. 1.

12. Bier M. C., Kohn S., Stierand A., Grimmelsmann N., Homburg S. V., Rattenholl A., Ehrmann A. IOP Conf. Ser.: Mater. Sci. Eng., 2017, vol. 254, p. 192004. DOI: 10.1088/1757-899X/254/19/192004

13. Cheema M., Hristov A. N., Harte F. M. J. Dairy Sci., 2017, vol. 100, iss. 11, pp. 8670-8679. DOI: http://dx.doi. org/10.3168/jds.2017-12631

14. Khafallah I., Boutebba A., Ali. T. J. Chem. Pharm. Res., 2015, vol. 7, p. 926-930.

15. Ruettimann K. W., Ladisch M. R. Enzyme Microb. Technol., 1987, vol. 9, pp. 578-579. DOI: https://doi. org/10.1016/0141-0229(87)90109-8

16. Farrell J. H. M., Malin E. L., Brown E. M., Qi P. X. Current Opinion in Colloid \& Interface Science, 2006, vol. 11, pp. 135-147. DOI: https://doi.org/10.1016/j. cocis.2005.11.005

17. Holt C., Carver J. A., Ecroyd H., Thorn D. C. Journal of Dairy Science, vol. 96, no. 10, 2013. p. 6127-6146. DOI: https://doi.org/10.3168/jds.2013-6831

18. Ferrandini E., Castillo M., Lypez M. B., Laencina J. // An. Vet. (Murcia), 2006, vol. 22, pp. 5-18.

19. Kinsella J. E. CRC Crit. Rev. Food Sci. Nutr., 1984, vol. 21, iss. 3, pp. 197-262. DOI: https://doi.org/10.1080/1 0408398409527401

20. Guadix A., Guadix E. M., Pбez-duecas M. P., Gonzбlez-tello P., Camacho F. Ars Pharmaceutica, 2000, vol. 41, no. 1, pp. 79-89.

21. Theвvenot D. R., Toth K., Durst R. A., Wilson G. S. Pure Appl. Chem., 1999, vol. 71, no. 12, pp. 2333-2348.

22. Bahr J. L.; Tour J. M. Chem. Mater., 2001, vol. 13, iss. 11, pp. 3823-3824. DOI: 10.1021/cm0109903 
Карлос Эдуардо Ангарита Лорес - аспирант кафедры физики полупроводников и микроэлектроники, Воронежский государственный университет; тел.: +7(920) 4027485, e-mail: loresruizlozano@, gmail.com

Долгих Игорь Игоревич - аспирант кафедры физики полупроводников и микроэлектроники, Воронежский государственный университет; тел.: +7(908) 1468527, e-mail: dolgih_igor@yahoo.com
Karlos Eduardo Angarita Lores - graduate student, Department of Physics of Semiconductors and Microelectronics, Voronezh State University; tel.: +7(920) 4027485, e-mail: loresruizlozano@gmail.com

Igor I. Dolgih - graduate student, Department of Physics of Semiconductors and Microelectronics, Voronezh State University; tel.: +7(908) 1468527, e-mail: dolgih_igor@yahoo.com 